\title{
Improving Antioxidant Activity of Ophioglossum thermale Kom. by Fermentation with Talaromyces purpurogenus M18-11
}

\author{
Jian-wei Dong, ${ }^{a, b}$ Le Cai, ${ }^{*, a}$ Xue-jiao Li, ${ }^{a}$ Rui-feng Mei, ${ }^{a}$ Ping Luo ${ }^{a}$ and \\ Zhong-tao Ding*,a \\ ${ }^{a}$ Functional Molecules Analysis and Biotransformation Key Laboratory of Universities in Yunnan Province, \\ School of Chemical Science and Technology, Yunnan University, 650091 Kunming, P.R. China \\ ${ }^{b}$ College of Chemistry and Environmental Science, Qujing Normal University, 655011 Qujing, P.R. China
}

\begin{abstract}
Ophioglossum thermale Kom. was fermented with several fungi. The total phenolic and flavonoid contents (TPCs and TFCs) and antioxidant activities of fermented and non-fermented $O$. thermale (FOT and NFOT) were investigated. The results showed that Talaromyces purpurogenus M18-11 fermented $O$. thermale possessed significantly improved TPC and TFC and exhibited significantly stronger 1,1-diphenyl-2-picrylhydrazyl (DPPH) (half maximal inhibitory concentration $\left(\mathrm{IC}_{50}\right)=75.7 \pm 2.1 \mu \mathrm{g} \mathrm{mL}^{-1}$ ) and 2,2'-azino-bis(3-ethylbenzothiazoline-6-sulfonic acid) diammonium salt (ABTS) $\left(\mathrm{IC}_{50}=20.52 \pm 1.68 \mu \mathrm{g} \mathrm{mL}^{-1}\right)$ free-radical scavenging activities, ferric reducing antioxidant power $\left(0.585 \pm 0.045 \mathrm{mmol} \mathrm{g}^{-1}\right)$, and reducing power (half maximal effective concentration $\left(\mathrm{EC}_{50}\right)=30.52 \pm 1.91 \mu \mathrm{g} \mathrm{mL^{-1 }}$ ) than original material. The determination of the contents of representative flavonoids and their glucosides revealed that the improvements are attributed to the hydrolysis of homoisoflavonoid and flavonoid glucosides, glycometabolism, as well as fungal metabolites. This paper is the first to report the fermentation of $O$. thermale with pure strains and T. purpurogenus is an effective strain to process $O$. thermale for improving the antioxidant activity.
\end{abstract}

Keywords: Ophioglossum thermale, Talaromyces purpurogenus, fermentation, antioxidant activity, flavonoid

\section{Introduction}

The genus Ophioglossum (Ophioglossaceae) is a small terrestrial plant that is distributed worldwide. ${ }^{1}$ Phytochemical researches revealed that the herb of Ophioglossum contains massive fatty acids and their esters, ${ }^{2,3}$ amino acid, ${ }^{4}$ flavonoids, ${ }^{5-11}$ and polysaccharoses. ${ }^{12,13}$ Ophioglossum thermale Kom., "Yizhijian" in traditional Chinese medicine (TCM), is a plant of the genus Ophioglossum, which is frequently used as a herbal medicine for clearing heat and detoxicating. Its main chemical constituents are flavonoids ${ }^{2,14,15}$ which possess significant antioxidant activity. ${ }^{7}$

Herbal fermentation processing began approximately 4000 years ago in China, which is frequently used to produce secondary metabolites from domestic plants in bulk by utilizing the metabolic mechanisms of microorganisms. Solid-state natural fermentation (SSF)

\footnotetext{
*e-mail: caile@ynu.edu.cn; ztding@ynu.edu.cn
}

was very popular in the processing of herbal medicines in ancient China, such as Semen Sojae Praeparatum, Mass Galla chinesis et camelliae Fermentata, Massa Medicata Fermentata, and Rhizoma Pinelliae Fermentata, etc. With the development of microbial technology, pure strain fermentation has become increasingly acceptable and reliable for processing herbal medicines in modern times. In recent years, some fermented traditional medicines (FTMs) have been reported. FTMs exhibit stronger biological activities or higher bioavailability in the human body compared with raw materials. For example, Hsu et al. ${ }^{16}$ reported that Bacillus subtilis fermented Radix astragali could stimulate the biosynthesis of type I procollagen in a dose-dependent manner in both aged and young human dermal fibroblast cells. Aspergillus oryzae-fermented Curcuma longa L. could effectively prevent $\mathrm{CCl}_{4}$-induced hepatic damage in rats. ${ }^{17}$ Wang et al. ${ }^{18}$ improved bioactivities of polyphenol extracts from Psidium guajava L. leaves by fermentation of Monascus anka and Saccharomyces cerevisiae. 
In the present study, the herb of $O$. thermale was fermented with several fungi. The 1,1-diphenyl-2-picrylhydrazyl (DPPH) and 2,2'-azino-bis(3-ethylbenzothiazoline6-sulfonic acid) diammonium salt (ABTS) radicalscavenging activities, reducing power, and ferric reducing antioxidant power (FRAP) of non-fermented and fermented $O$. thermale (FOT) were determined for evaluating their antioxidant activities. Talaromyces purpurogenus M1811 was screened to process $O$. thermale for improving the antioxidant activity. Further total phenolic and flavonoid contents (TPCs and TFCs) determination and highperformance liquid chromatography (HPLC) analysis were used for explaining the changes of antioxidant.

\section{Experimental}

\section{Chemicals}

ABTS, DPPH, 2,4,6-tri(2-pyridyl)-1,3,5-triazine (TPTZ), and 6-hydroxy-2,5,7,8-tetramethylchroman2-carboxylic acid (Trolox) were obtained from J\&K Scientific Ltd. (Beijing, China). Rutin and gallic acid were purchased from Aladdin-Reagent (Shanghai, China). Luteolin (1), quercetin (2), 3-methoxyquercetin (3), ophioglonol (4), ophioglonol 4'-O- $\alpha$-D-glucopyranoside (5), and pedunculosumoside B (6) used in the present study were isolated from $O$. thermale. ${ }^{14}$ The water (resistivity $\geq 18.25 \mathrm{M} \Omega \mathrm{cm}$ ) used was purified with a purity water system (Chengdu, China). All other chemicals used were of analytical grade.

\section{Plant material}

The herbs of $O$. thermale were collected from Wenshan, Yunnan, China, in February 2014, and were identified by Assistant Professor Shu-Da Yang from School of Pharmacy, Kunming Medical University, Kunming, China. A voucher specimen (2014-0t-01) has been deposited in School of Chemical Science and Technology, Yunnan University, Kunming, China.

\section{Microorganisms and fermentation}

All strains including T. purpurogenus M18-11, Aspergillus niger YIM3029, Geomyces luteus P18-5, and Penicillium swiecickii F2-7 were obtained from Yunnan Institute of Microbiology, Yunnan Province, China.

Potato dextrose agar (PDA; $1 \mathrm{~L}$ water, $200 \mathrm{~g}$ potato, $20 \mathrm{~g}$ dextrose, and $15 \mathrm{~g}$ agar) slant culture mediums were inoculated with fungi above and incubated in a constant temperature incubator at $28{ }^{\circ} \mathrm{C}$ for 5 days. Five grams of
O. thermale were added to a $100 \mathrm{~mL}$ Erlenmeyer flask to function as the fermentation culture medium. After being infiltrated with $15 \mathrm{~mL}$ water and sterilized at $121{ }^{\circ} \mathrm{C}$ for $30 \mathrm{~min}$, the mature slants culture mediums were added and incubated at $28^{\circ} \mathrm{C}$ for 30 days.

\section{Extraction}

O. thermale $(5.0 \mathrm{~g})$ and each of the four individual FOTs were immersed in $50 \mathrm{~mL}$ acetone for $24 \mathrm{~h}$ and ultrasonicated three times for $30 \mathrm{~min}$ each time. The extracting solution was decanted, filtered under vacuum and concentrated in a rotary evaporator to afford five extracts: ROT (raw O. thermale, $1.063 \mathrm{~g}$ ), BFOT (blank FOT, 1.099 g), FOT1 (A. niger FOT, 0.405 g), FOT2 (T. purpurogenus FOT, $0.549 \mathrm{~g}$ ), FOT3 (G. luteus FOT, $0.667 \mathrm{~g}$ ), and FOT4 (P. swiecickii FOT, $0.475 \mathrm{~g}$ ).

\section{Antioxidant activities}

\section{DPPH radical-scavenging activity}

The DPPH free radical-scavenging activity was estimated by the method described previously. ${ }^{19} \mathrm{DPPH}$ radical-scavenging activity of the sample was calculated as follows:

Inhibition $(\%)=\left(1-\mathrm{A}_{\text {sample }}^{\mathrm{DPPH}} / \mathrm{A}_{\text {control }}^{\mathrm{DPPH}}\right) \times 100$

where $A_{\text {sample }}^{\mathrm{DPPH}}$ is the absorbance of sample solution mixed with DPPH and $A_{\text {control }}^{\mathrm{DPPH}}$ is the absorbance of the blank solution (ethanol). Rutin was used as a positive control. All tests were performed in triplicate. The half maximal inhibitory concentration $\left(\mathrm{IC}_{50}\right)$ value was defined as the effective concentration at which the DPPH radical was scavenged by $50 \%$. Anti-radical power (ARP) was defined as $1 / \mathrm{IC}_{50} . \mathrm{ARP}_{\mathrm{i}}$ and $\mathrm{ARP}_{0}$ were represented as the $\mathrm{ARP}$ of each sample and ROT, respectively.

\section{ABTS assay}

ABTS antioxidant capacity was measured using a previous ABTS method. ${ }^{19,20}$ ABTS radical-scavenging activity was calculated as follows:

Inhibition $(\%)=\left(1-\mathrm{A}_{\text {sample }}^{\mathrm{ABTS}} / \mathrm{A}_{\text {control }}^{\mathrm{ABTS}}\right) \times 100$

where $A_{\text {sample }}^{\mathrm{ABTS}}$ is the absorbance of sample solution mixed with $\mathrm{ABTS}$ and $\mathrm{A}_{\text {control }}^{\mathrm{ABTS}}$ is the absorbance of the blank solution. The $\mathrm{IC}_{50}$ value was defined as the effective concentration at which the ABTS radical was scavenged by $50 \%$. ARP was defined as $1 / \mathrm{IC}_{50}$. $\mathrm{ARP}_{\mathrm{i}}$ and $\mathrm{ARP}_{0}$ were represented as the ARP of each sample and ROT, respectively. 
FRAP

The FRAP assay measures the reduction of ferric iron to the ferrous form in the presence of antioxidants. The assay protocol followed a previously reported procedure. ${ }^{21}$ The antioxidant capacity of the sample was expressed as $\mu$ mol ferrous sulfate per $\mathrm{g}$ extract $\left(\mu \mathrm{mol} \mathrm{g}^{-1}\right.$ ), which was calculated from the standard graph obtained with the ferrous sulfate solution.

\section{Reducing power}

Reducing power was tested using a reported method. ${ }^{22,23}$ $100 \mu \mathrm{L}$ of sample at proper concentration was made up to $0.75 \mathrm{~mL}$ with phosphate buffer (300 mM, pH 6.6), and $1.5 \mathrm{~mL}$ of $1 \%(\mathrm{~m} / \mathrm{v}) \mathrm{K}_{3} \mathrm{Fe}(\mathrm{CN})_{6}$ was added. The mixture was shaken vigorously and left to stand for $20 \mathrm{~min}$ at $50{ }^{\circ} \mathrm{C}$. After the addition of $1.5 \mathrm{~mL}$ of $10 \%(\mathrm{~m} / \mathrm{v})$ trichloroacetic acid, the mixture was centrifuged at $3000 \mathrm{rpm}$ for $10 \mathrm{~min}$. A $1.5 \mathrm{~mL}$ of supernatant was mixed with distilled water $(1.5 \mathrm{~mL})$, and $0.3 \mathrm{~mL}$ of $0.1 \%(\mathrm{~m} / \mathrm{m}) \mathrm{FeCl}_{3}$ was added before the absorbance was determined at $700 \mathrm{~nm}$. Half maximal effective concentration $\left(\mathrm{EC}_{50}\right)$ was defined by the concentration at absorbance $(\mathrm{A})=0.50$; antioxidant reducing power (ARP) was defined as $1 / \mathrm{EC}_{50} . \mathrm{ARP}_{\mathrm{i}}$ and $\mathrm{ARP}_{0}$ were represented as the ARP of each sample and ROT, respectively.

\section{Determination of total phenolic content}

The total phenolic content was measured using the FolinCiocalteau method. ${ }^{24}$ Folin-Ciocalteu's reagent was prepared according to the method of GB/T 23527-2009 (CN). ${ }^{25}$ Fifty microliters of extract solution was added to $2.25 \mathrm{~mL}$ of Folin-Ciocalteu's reagent, which was pre-diluted ten-fold with distilled water. Five minutes later, $1.5 \mathrm{~mL}$ of $\mathrm{Na}_{2} \mathrm{CO}_{3}$ $(7.5 \%, \mathrm{~m} / \mathrm{v})$ solution was added, and the mixture was allowed to stand for $30 \mathrm{~min}$ at ambient temperature. Absorbance was measured at $765 \mathrm{~nm}$. The TPC was expressed as $\mathrm{mg}$ gallic acid equivalent per $\mathrm{g}$ extract (mg GAE $\mathrm{g}^{-1}$ ) and calculated according to the calibration curve obtained from the standard solution of gallic acid at various concentrations.

\section{Determination of total flavonoid content}

The total flavonoid content was determined by a colorimetric assay described previously. ${ }^{23,26}$ The total flavonoid content was expressed as $\mathrm{mg}$ rutin equivalent perg $\left(\mathrm{mg} \mathrm{RE} \mathrm{g}^{-1}\right)$.

\section{HPLC analysis}

The determination and quantification of main flavonoids compounds were measured using an Agilent 1260 Infinity Series HPLC system, equipped with an Agilent G1315D DAD detector, an Agilent G1311C quaternary gradient pump, and Agilent Zorbax SB-C18 $(250 \times 4.6 \mathrm{~mm}$ i.d., $5 \mu \mathrm{m})$, and coupled to an Agilent OpenLab data-processing station. A gradient elution system consisting of solvent A (water containing $6 \mathrm{mM}$ acetic acid) and B (acetonitrile) was used for the analysis, and the gradient program was as follows: 0-25 min, 15-65\%B; 25-30 min, 65-100\%B; 30-35 min, 100\%B. The peaks were confirmed by the UV absorptions at 320 and $355 \mathrm{~nm}$ and the retention times while the flow rate

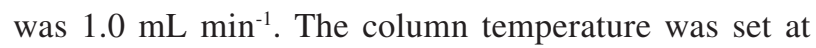
$35{ }^{\circ} \mathrm{C}$, and the injection volume was $20 \mu \mathrm{L}$. Flavonoids were identified by using standard addition method, and quantified according to standard curves.

\section{Results and Discussion}

After fermentation of $O$. thermale with several fungi, a preliminary experiment by thin layer chromatography (TLC) was measured. Four fermented samples were selected for further experiments.

\section{Antioxidant activities}

Oxidation is ubiquitous and has pernicious effects on both food quality and human health. Previous research indicated that oxidative damage can cause browning and off-flavors, change the nutrient value of food, disrupt cellular function and attenuate the formation of compounds used to fight aging and cardio-vascular disease. ${ }^{27}$ Zhang et al. ${ }^{7}$ reported that the extract of $O$. thermale possesses antioxidant activity. In the present study, therefore, the antioxidant activity of ROT, BFOT, and FOT1-4 were tested.

DPPH is a stable free radical that has been used widely to determine the free radical-scavenging activity of natural antioxidants. The DPPH radical scavenging activities shown in Figure 1 revealed that FOT1-3 exhibited more significant activities than ROT, BFOT, and FOT4, in particular, FOT2 possessed 2-fold more antioxidant activity with an $\mathrm{IC}_{50}$ value of $75.7 \pm 2.1 \mu \mathrm{g} \mathrm{mL} \mathrm{m}^{-1}$ than ROT.

ABTS is another free radical that is frequently used to study free radical-scavenging activity. Notably, the ABTS radical-scavenging activity assay is an important indicator of total antioxidant activity (TAA). As shown in Figure 2, FOT1-3 showed stronger ABTS radicalscavenging activities with the $\mathrm{IC}_{50}$ values of $18.61 \pm 1.32$, $20.52 \pm 1.68$, and $19.20 \pm 0.92 \mu \mathrm{g} \mathrm{mL}{ }^{-1}$, than FOT and BFOT. 


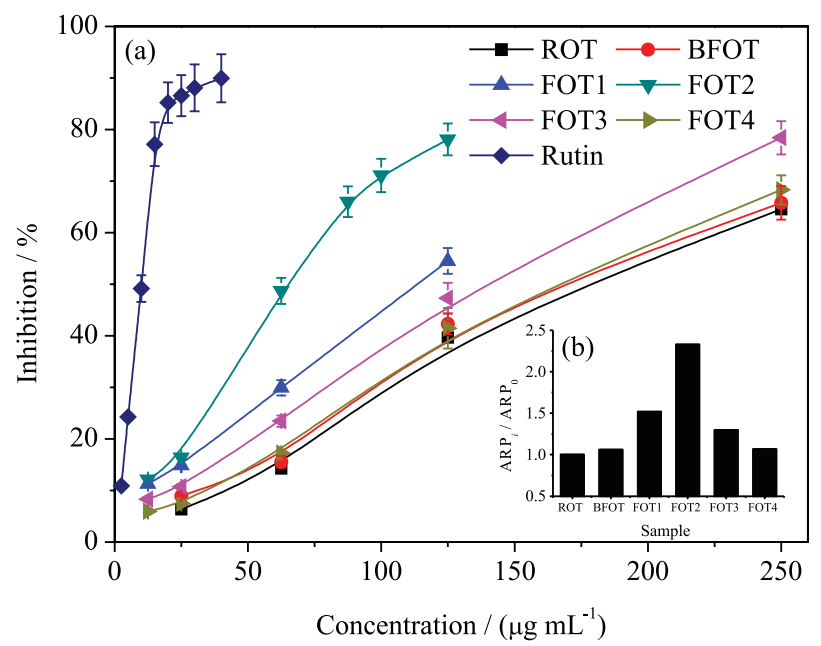

Figure 1. DPPH radical scavenging activities of the extracts of ROT, BFOT, and FOT1-4. (a) Inhibition of DPPH radical scavenging activities at different concentrations; (b) relative $\mathrm{ARP}\left(\mathrm{ARP}_{\mathrm{i}} / \mathrm{ARP}_{0}\right)$ of $\mathrm{BFOT}$ and FOT1-4.

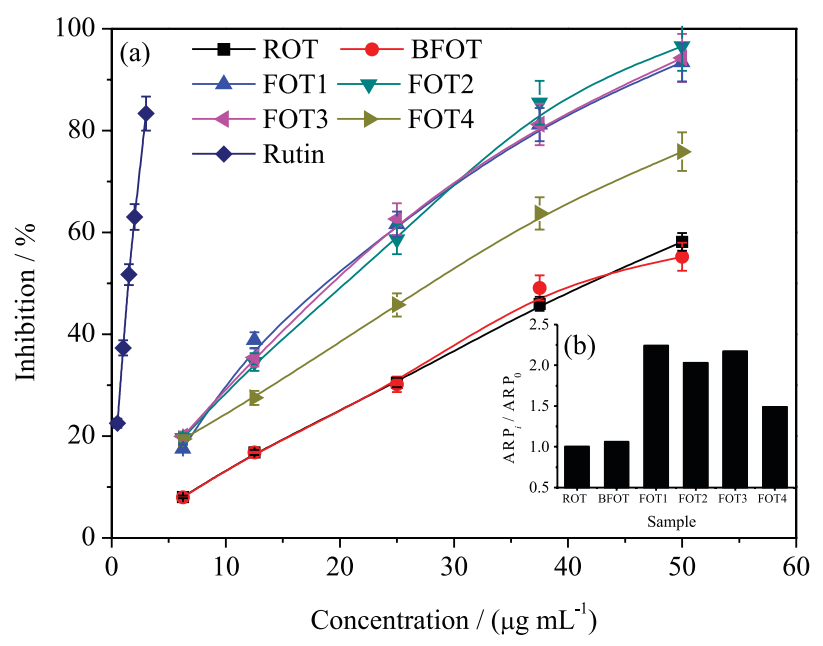

Figure 2. ABTS radical scavenging activities of the extracts of ROT, BFOT, and FOT1-4. (a) Inhibition of ABTS radical scavenging activities at different concentrations; (b) relative $\mathrm{ARP}\left(\mathrm{ARP}_{\mathrm{i}} / \mathrm{ARP}_{0}\right)$ of $\mathrm{BFOT}$ and FOT1-4.

Reducing power of the natural plant extracts might be strongly correlated with their antioxidant activity. It is necessary to discuss the reducing power of a natural plant extract to elucidate the relationship between its antioxidant effect and reducing power. The results shown in Figure 3 suggest FOT2 exhibits significantly improved reducing power with an $\mathrm{EC}_{50}$ value of $30.52 \pm 1.91 \mu \mathrm{g} \mathrm{mL}^{-1}$. The FRAP is often used as an indicator of phenolic antioxidant activity as important as reducing power. The antioxidant potential of sample was estimated by their abilities, which is to reduce Fe ${ }^{\mathrm{III}}$-TPTZ to $\mathrm{Fe}^{\mathrm{II}}$-TPTZ. Similar to reducing power, FOT2 possessed improved antioxidant activity $\left(0.585 \pm 0.045 \mathrm{mmol} \mathrm{g}^{-1}\right.$, Figure 4$)$.

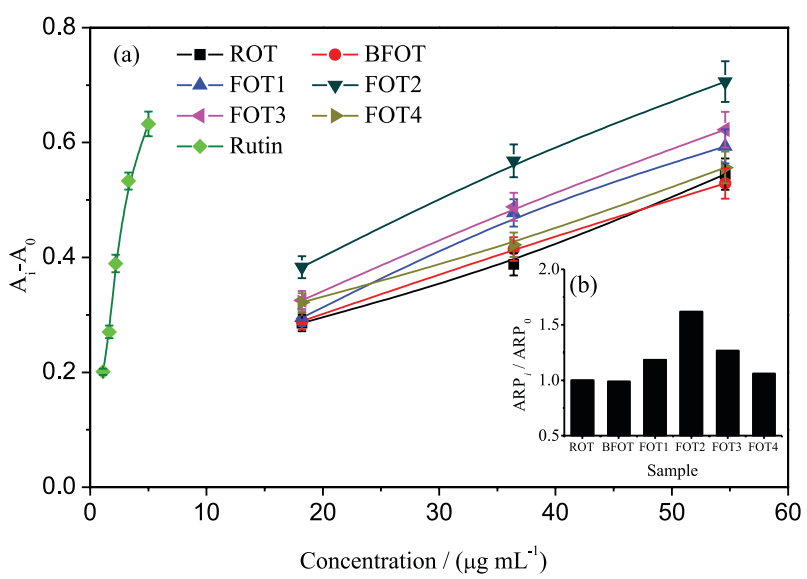

Figure 3. Reducing powers of the extracts of ROT, BFOT, and FOT1-4. (a) Reducing powers at different concentrations; (b) relative ARP $\left(\mathrm{ARP}_{\mathrm{i}} / \mathrm{ARP}_{0}\right)$ of BFOT and FOT1-4.

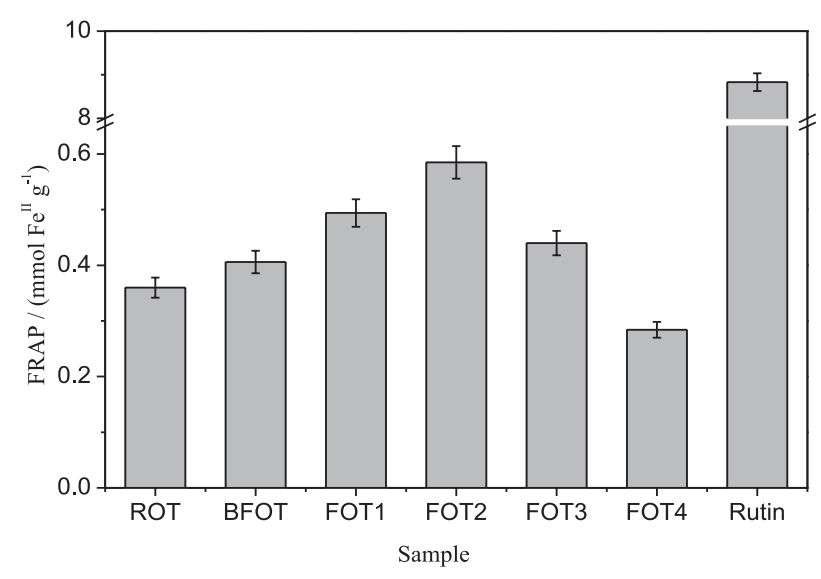

Figure 4. FRAP of the extracts of ROT, BFOT, and FOT1-4.

In addition, the DPPH antioxidant activity for extract of fungal strains A. niger, T. purpurogenus, G. luteus, and $P$. swiecickii, individually cultured in PDA medium was $390.8 \pm 25.1,235.8 \pm 21.1,234.4 \pm 10.9$, $235.2 \pm 31.2 \mu \mathrm{g} \mathrm{mL}^{-1}$, respectively (for pure PDA medium, it was $386.5 \pm 29.1 \mu \mathrm{g} \mathrm{mL}^{-1}$ ). Therefore, the results above show that FOT2 exhibits significantly improved antioxidant activity, suggesting that fermentation of $O$. thermale with $T$. purpurogenus might be effective for improving antioxidant activity.

\section{Total phenolic content (TPC)}

Phenolic content always shows potent antioxidant activity, in particular, radical-scavenging power. In the present study, the improvement of antioxidant activity might be ascribed to changes of phenolic constituents. Hence, the TPCs of ROT, BFOT, and FOT1-4 were evaluated and the results were shown in Figure 5. The values of TPCs were expressed as 


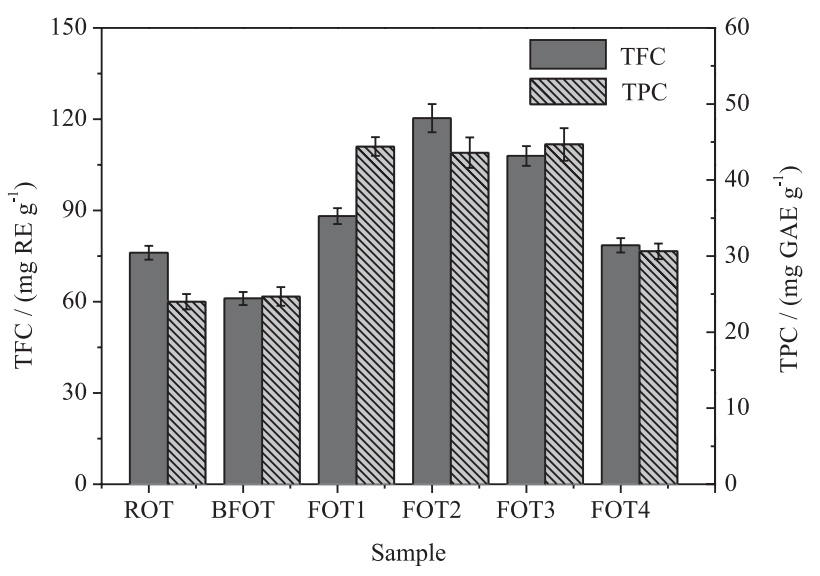

Figure 5. TPCs and TFCs of the extracts of ROT, BFOT, and FOT1-4.

mg GAE $\mathrm{g}^{-1}$ and decreased in the following order: FOT1-3 $\left(44.41 \pm 1.22,43.63 \pm 2.00,44.69 \pm 2.13 \mathrm{mg} \mathrm{g}^{-1}\right)>>$ FOT 4 $\left(30.63 \pm 1.03 \mathrm{mg} \mathrm{g}^{-1}\right)>\operatorname{ROT}\left(24.01 \pm 1.00 \mathrm{mg} \mathrm{g}^{-1}\right) \approx$ BFOT $\left(24.69 \pm 1.23 \mathrm{mg} \mathrm{g}^{-1}\right)$, suggesting A. niger, T. purpurogenus, and G. luteus fermentation might improve the TPC of O. thermale.

Total flavonoid content (TFC)

As the main constituents of $O$. thermale are flavonoids including quercetin, 3-methoxyquercetin, ophioglonol and their esters, the TFCs of the fermented and non-fermented materials are indicators for evaluating the effects of fermentation. The TFCs of ROT, BFOT, and FOT1-4 are shown in Figure 5. FOT2 and FOT3 possessed obvious improved TFCs with the values of $120.35 \pm 0.84$ and $107.94 \pm 4.22 \mathrm{mg} \mathrm{RE} \mathrm{g}^{-1}$, respectively, whereas FOT1, FOT4, and BFOT exhibited TFC with same grade as ROT.

These results suggest that $T$. purpurogenus might be an effective strain for processing $O$. thermale for improving the TPC, TFC, and antioxidant activity. The improvement of antioxidant activity might be caused by the changes of flavonoids, as well as fungal metabolites produced by fungi during fermentation.

\section{HPLC analysis}

To clarify the flavonoids, it was performed positive antioxidant activities in the fermented and non-fermented $O$. thermale. HPLC was employed to identify the changes of main flavonoids isolated from $O$. thermale. Six main flavonoid compounds isolated from $O$. thermale, luteolin (1), quercetin (2), 3-methoxyquercetin (3), ophioglonol (4), ophioglonol 4'-O- $\alpha$-D-glucopyranoside (5), and pedunculosumoside B (6) (Figure 6) were used to identify the peaks in chromatograms of ROT, BFOT, and T. purpurogenus FOT. As shown in Figure 7, flavonoid glucoside 5 could be not detected in T. purpurogenus FOT, suggesting that flavonoid glucosides are hydrolyzed by T. purpurogenus-fermentation. The peaks at 30-35 min observed in ROT disappeared after fermentation, suggesting that some low-polarity constituents are metabolized leading to the enrichment of the flavonoids. The contents of three main flavonoids 3-5 were determined by HPLC. The results in Table 1 show that the contents of flavonoid aglycones $\mathbf{3}$ and $\mathbf{4}$ were enriched. This might be caused by the hydrolysis of flavonoid glucosides and glycometabolism.

\section{Antioxidant activities of flavonoid compounds 1-6}

The DPPH radical-scavenging activities of flavonoid aglycones 1-4 and glucosides 5 and $\mathbf{6}$ were determined to evaluate the difference of antioxidant activities between flavonoid aglycones and glucosides. The results shown in Table 2 reveal that flavonoid aglycones 1-4 exhibited more significant DPPH radical-scavenging power $\left(\mathrm{IC}_{50}<10 \mu \mathrm{g} \mathrm{mL}^{-1}\right)$ than flavonoid glucosides

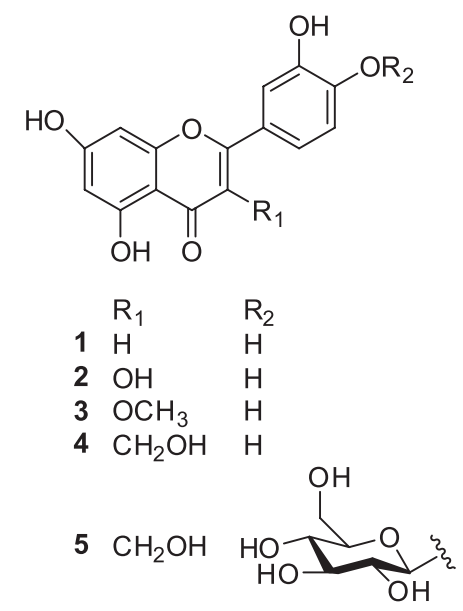<smiles>CC(C)=CCc1cc(-c2oc3cc(OC4CC(O)C(O)C(O)C4O)cc(O)c3c(=O)c2CO)cc(O)c1OC1OC2OC1C(O)C(O)C(O)C(O)C(O)C2O</smiles>

Figure 6. Structures of main flavonoid compounds. 

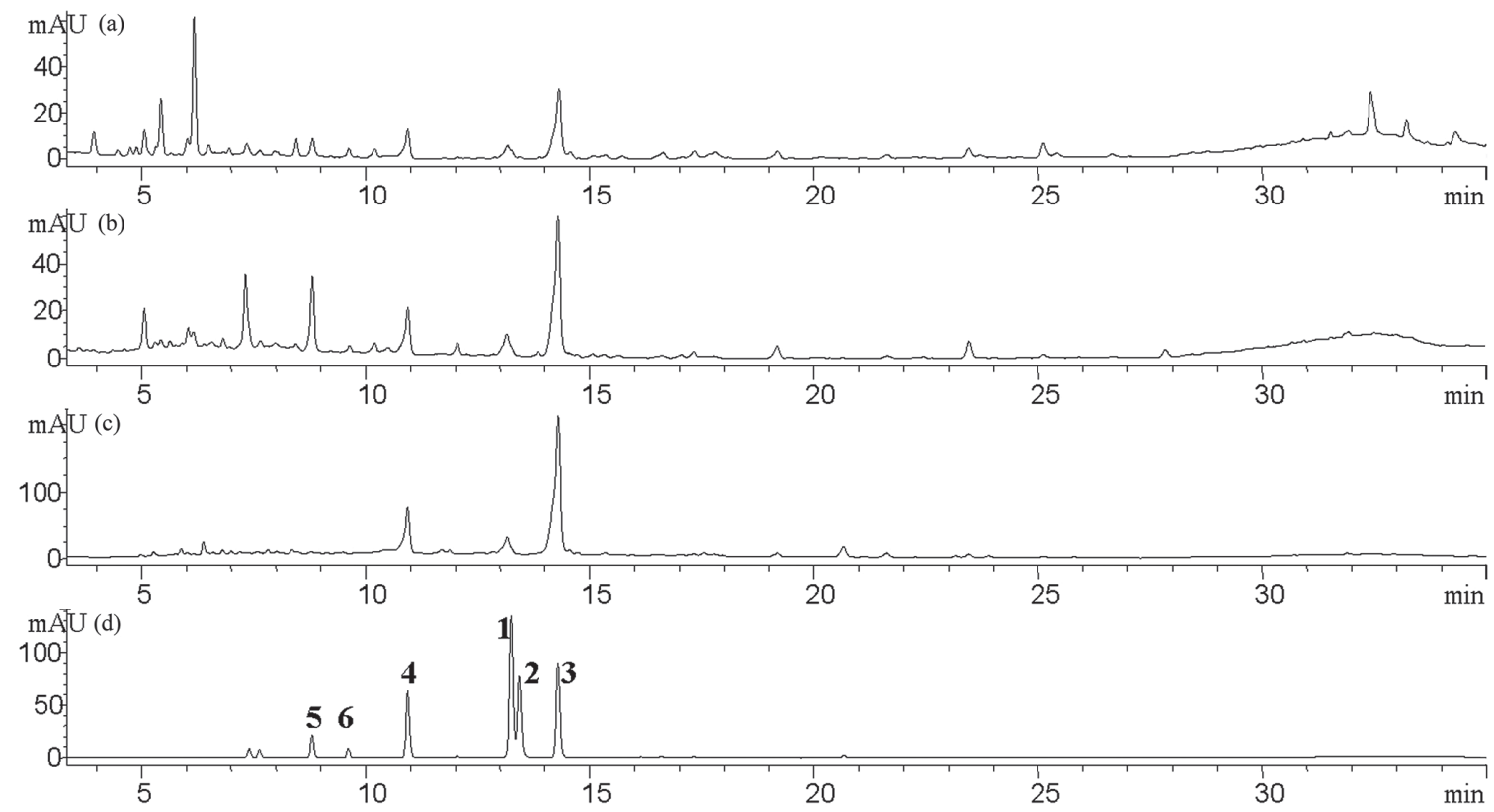

Figure 7. Chromatograms of (a) ROT; (b) BFOT; (c) T. purpurogenus FOT; (d) compounds 1-6.

Table 1. The contents of compounds 3-5 in non-fermented and fermented o. thermale

\begin{tabular}{lccc}
\hline Sample & 3 / (mg per $100 \mathrm{~g})$ & 4 / (mg per $100 \mathrm{~g})$ & $\mathbf{5} /(\mathrm{mg}$ per $100 \mathrm{~g})$ \\
\hline ROT & $3.92 \pm 0.94$ & $16.88 \pm 0.81$ & $15.18 \pm 1.18$ \\
BFOT & $6.76 \pm 0.51$ & $17.08 \pm 0.43$ & $15.30 \pm 2.55$ \\
FOT2 & $17.64 \pm 0.42$ & $44.62 \pm 0.14$ & $\mathrm{nd}^{\mathrm{a}}$ \\
\hline
\end{tabular}

aNot detected. ROT: raw $O$. thermale; BFOT: blank fermented $O$. thermale; FOT2: T. purpurogenus FOT.

Table 2. DPPH radical-scavenging activities $\left(\mathrm{IC}_{50}\right)$ of compounds 1-6

\begin{tabular}{lcc}
\hline Sample & $\mathrm{IC}_{50} /\left(\mu \mathrm{g} \mathrm{mL}^{-1}\right)$ & $\mathrm{IC}_{50} / \mu \mathrm{M}$ \\
\hline $\mathbf{1}$ & $7.53 \pm 0.10$ & $26.3 \pm 0.4$ \\
$\mathbf{2}$ & $2.86 \pm 0.09$ & $9.5 \pm 0.3$ \\
$\mathbf{3}$ & $9.11 \pm 0.73$ & $28.8 \pm 2.3$ \\
$\mathbf{4}$ & $8.31 \pm 0.49$ & $26.3 \pm 1.6$ \\
$\mathbf{5}$ & $56.9 \pm 2.64$ & $115.2 \pm 5.3$ \\
$\mathbf{6}$ & $61.32 \pm 5.87$ & $86.6 \pm 8.3$ \\
Rutin $^{\mathrm{a}}$ & $8.20 \pm 0.05$ & $13.4 \pm 0.1$ \\
\hline
\end{tabular}

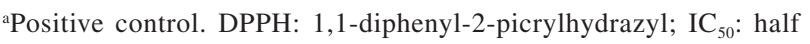
maximal inhibitory concentration.

$\left(\mathrm{IC}_{50}>50 \mu \mathrm{g} \mathrm{mL} \mathrm{L}^{-1}\right)$. Therefore, hydrolysis of flavonoid glucosides in $O$. thermale could enrich the flavonoid aglycones, improving the antioxidant activity of $O$. thermale.

\section{Conclusions}

The present study is the first to report that pure strain fermentation processing is effective in improving the TPC,
TFC, and antioxidant activity of $O$. thermale. Fermentation with $T$. purpurogenus could be an innovative approach to process $O$. thermale. TFC and antioxidant activity enhancements with $T$. purpurogenus might be attributed to hydrolysis of flavonoid glycosides, decomposition of glycoside and other low-polarity constituents, and fungal metabolites.

\section{Acknowledgments}

This work was financially supported by a grant from the Natural Science Foundation of China (No. 81660719), a grant from the Natural Science Foundation of Yunnan Province, a grant of Yunnan Local Colleges Applied Basic Research Project (No. 2017FH001-092), a project of Yunling Scholars of Yunnan Province, the Program for Excellent Young Talents, Yunnan University, a grant from Shanghai Key Laboratory of Rare Earth Functional Materials, and a grant from Functional Molecules Analysis and Biotransformation Key Laboratory of Universities in Yunnan Province.

\section{References}

1. Flora of China Editorial Committee; Flora Reipublicae Popularis Sinicae; Science Press: Beijing, China, 1959.

2. Zhang, G. W.; Wu, N. Z.; Fan, Q.; Zhou, X. L.; Huang, S.; Nat. Prod. Res. Dev. 2010, 22, 1006.

3. Clericuzio, M.; Burlando, B.; Gandini, G.; Tinello, S.; Ranzato, E.; Martinotti, S.; Cornara, L.; J. Nat. Med. 2014, 68, 31.

4. Khandelwal, S.; Biochem. Syst. Ecol. 1989, 17, 167. 
5. Lin, Y. L.; Shen, C. C.; Huang, Y. J.; Chang, Y. Y.; J. Nat. Prod. 2005, 68, 381.

6. Wan, C. X.; Zhang, P. H.; Luo, J. G.; Kong, L. Y.; J. Nat. Prod. 2011, 74, 683.

7. Zhang, X. Q.; Kim, J. H.; Lee, G. S.; Pyo, H. B.; Shin, E. Y.; Kim, E. G.; Zhang, Y. H.; Am. J. Chin. Med. 2012, 40, 279.

8. Wan, C.-X.; Luo, J.-G.; Gu, Y.-C.; Xu, D.-R.; Kong, L.-Y.; Phytochem. Anal. 2013, 24, 541.

9. Clericuzio, M.; Tinello, S.; Burlando, B.; Ranzato, E.; Martinotti, S.; Cornara, L.; La, R. A.; Planta Med. 2012, 78, 1639.

10. Wan, C.-X.; Luo, J.-G.; Gu, Y.-C.; Kong, L.-Y.; J. Asian Nat. Prod. Res. 2012, 14, 533.

11. Markham, K. R.; Mabry, T. J.; Voirin, B.; Phytochemistry 1969 , $8,469$.

12. Xue, X.; Fry, S. C.; Ann. Bot. 2012, 109, 873.

13. He, X. M.; Ji, N.; Xiang, X. C.; Luo, P.; Bao, J. K.; Appl. Biochem. Biotechnol. 2011, 165, 1458.

14. Dong, J. W.; Cai, C.; Li, X. J.; Peng, L.; Xing, Y.; Mei, R. F.; Wang, J. P.; Ding, Z. T.; Fitoterapia 2016, 109, 212.

15. Hu, W. C.; Zhou, Z. B.; Wang, C. X.; J. Chin. Med. Mater. 2016, 39, 1035.

16. Hsu, M. F.; Chiang, B. H.; Process Biochem. 2009, 44, 83.

17. Kim, Y.; You, Y.; Yoon, H. G.; Lee, Y. H.; Kim, K.; Lee, J.; Kim, M. S.; Kim, J. C.; Jun, W.; Food Chem. 2014, 151, 148.
18. Wang, L.; Wei, W.; Tian, X.; Shi, K.; Wu, Z.; Ind. Crops Prod. 2016, 94, 206.

19. Dong, J. W.; Cai, L.; Xiong, J.; Chen, X. H.; Wang, W. Y.; Shen, N.; Liu, B. L.; Ding, Z. T.; Process Biochem. 2015, 50, 8.

20. Re, R.; Pellegrini, N.; Proteggente, A.; Pannala, A.; Yang, M.; Rice-Evans, C.; Free Radical Biol. Med. 1999, 26, 1231.

21. Suárez, B.; Álvarez, Á. L.; García, Y. D.; Barrio, G.; Lobo, A. P.; Parra, F.; Food Chem. 2010, 120, 339.

22. Dong, J. W.; Cai, L.; Zhu, X. F.; Huang, X.; Yin, T. P.; Fang, H. X.; Ding, Z. T.; J. Braz. Chem. Soc. 2014, 25, 1956.

23. Oyaizu, M.; Jpn. J. Nutr. 1986, 44, 307.

24. Singleton, V. L.; Rossi, J. A. J.; Am. J. Enol. Vitic. 1965, 16, 144.

25. GB/T 23527-2009: Protease Preparations, Administration of Quality Supervision, Inspection and Quarantine of People's Republic of China; Standardization Administration of China: China, 2009 (in Chinese).

26. Zhi, S. J.; Meng, C. T.; Jian, M. W.; Food Chem. 1999, 64, 555.

27. Cardenia, V.; Rodriguez-Estrada, M. T.; Boselli, E.; Lercker, G.; Biochimie 2013, 95, 473. 